\title{
The Attitudes of the Holy Land Institute for the Deaf-Salt, Jordan towards Deaf Socially and Educationally
}

\author{
Ayed H. Ziadat ${ }^{1} \&$ Fatima A. Atiyat ${ }^{2}$ \\ ${ }^{1}$ Department of Special Education, Princess Rahma College, Al-Balqa’ Applied University, Al-Salt, Jordan \\ 2 Department of Social Work, Princess Rahma College, Al-Balqa' Applied University, Al-Salt, Jordan \\ Correspondence: Ayed H. Ziadat, Princess Rahma College, Al-Balqa’ Applied University, Al-Salt, Jordan. \\ E-mail: ayedziadat@yahoo.com
}

Received: September 9, 2017

Accepted: October 6, $2017 \quad$ Online Published: October 24, 2017

doi:10.5539/jel.v7n1p142

URL: https://doi.org/10.5539/jel.v7n1p142

\begin{abstract}
The study aimed to recognize the attitudes of the Holy Land Institute for the Deaf-Salt, Jordan towards Deaf Socially and Educationally in the academic year 2016-2017, which consists of instructional and vocational staff towards deaf socially and educationally according to some variables (gender, age, the level of education). The sample of the study included staff members of the institution. The researchers used the Third Likert-Type and the descriptive approach. The sample of the study consisted of 69 persons whose answers achieved the required conditions. The results showed a decrease in the negative attitudes level, which reflected high positive attitudes according to the treatment of the study sample with deaf socially and educationally. Results also showed no significant differences refer to gender and age due to the attitudes. But there were significant differences due to the educational level of the workers in this institution giving advantage to the academic certificate and over, which means there were huge effects to the academic level in the social and educational attitudes towards the deaf.

The study recommended the importance of spreading and increasing the level of awareness among the people who work in this institute to the local society about how to cope with positive social and educational attitudes in order to increase the level of the deaf adaption and spread the culture of respecting the categories.
\end{abstract}

Keywords: the Holy Land Institute for the Deaf-Attitudes-the Deaf, Salt, Jordan

\section{Introduction}

People in general look to disabled people negatively in most societies. They also considered them as they are different people according to their characteristics and their personal abilities. The attitudes range between positive and negative. Some of them considered those people feel a kind of lack that represents their weakness and their continuous need to help, sympathy and petty. Others don't try to deal with them. They thought that those people (the deaf) are negative and aggressive people (Al-Rosan, 1998).

In general, some studies refer to significant disparity in attitudes and reactions of normal people towards those people of disability; because they form special attitudes and feelings towards themselves. That leads to depression and emotional disturbances result in double disability with them. Moreover, there may be appear in them deviations and behavior interruption from social standards and habitual activities such as heel, crime, aggression, feeling lack of respect, inability to self-reliance or co-operating with others, the lack of sharing work with other people, weakness in dealing with social habits, handicapped actions, copping with environment, reliance, and inability to engage with society or belonging to it, to families or to friends without direct supervision from their parents or from those who take care of them (Mprah, 2013).

On the other hand, we find many positive attitudes among some normal people who deal with deaf directly, daily and for a long period. This may give them a chance to understand and percept many facts about their personal, social, educational and behavioral deaf characteristics. This may lead to change their points of views and their attitudes (Ting \& Gilmore, 2012).

For a further in-depth look, this study tried to recognize the Social and Educational Attitudes of all the workers (males \& females) of the Holy Land Institute for the Deaf-Salt, Jordan towards Deaf, who beneficial from the services of this institution due to some variables (gender, age, and level of certification)? And also to recognize 
the level of adaption of different deaf people in this institute and the ambit of acquisition of their daily life, social, educational and instructional skills or as being known (social stabilization). According to the study and analysis the data from members of sample study, who are in contact with deaf people daily and continuously by providing all kind of services for them like (care, social, instructional, educational and vocational services). These services applied by different types of programs according to the institute philosophy and directions which are suitable with the needs of deaf people (Reports of Circular the Holly Land Institute for Deaf-Salt, Jordan, 1964-2017).

\subsection{Problem Statement}

The deaf people (with all their disabled categories) considered to be neglected in societies. This refers to many different negative attitudes toward them which emphasized by many studies all over the world that held according to the nature of societies, social and educational attitudes to this group (AL-Khateeb, 2009). These attitudes range between hatred, rejection, exclusion, irony and many bad expressions and social stigma. This reproduced different forms of behaviors such as (not connecting with normal people, ignorance in different life situations and leave them in social isolation and loneliness) (Maprah, 2013; AL-Khateeb, 1997).

Its worth to note that there is another positive face to those attitudes toward these categories, which observed by different ways such as respecting, accepting them, intimacy that depends on comprehensive details of the deaf people. Moreover, the interaction and social connection which happened between normal and the deaf people in the same institute which take care of deaf people as a residential institution (Moufdi, 2009). Leads to increase the odds of social interaction between the deaf and workers in this institute and also to exchange the attitudes from negative into positive. This achieved by using many different types of programs such as caring, instructional, educational, vocational, social and affluence activities all the time (Reports and circular of Holly Land Institute for Deaf-Salt, Jordan, 1964-2017).

These programs focused on how to build the social, educational and economic abilities which are known as (social stabilization) for this category. So they may face weakness, disability, shortage and isolation (Abu-AL-Futouh, 2011).

To make sure the role of interaction and social connection between workers at the institute and the deaf, this study focused and spot on the relationship between them and to recognize their adaption level. It also focused on their acquisition to the daily life skills, social, instructional and educational skills, which qualify them to depend on themselves in order to achieve their different basic needs and secondary needs, get along their subsistence among learning and working opportunities and joining in daily life activities in general by studying and analyzing the data that gathered from members of the study population to this study (AL-Khateeb, 2009).

\subsection{Purpose of the Study}

- To recognize the social and educational attitudes of (H.L.I.D) workers towards deaf people in general.

- To recognize the social attitudes of (H.L.I.D) administrative, instructional and vocational workers towards deaf people.

- To recognize the educational attitudes of (H.L.I.D) instructional and vocational workers towards deaf people.

- To recognize the effectiveness of different variables (gender, age, educational level of study population of (H.L.I.D) to form and point attitudes towards the deaf people among this institute.

\subsection{Hypothesis}

This study tried to answer the following questions:

1) What is the social and educational attitudes level of members of (M.L.I.D) in general?

2) What is the level of the social attitudes of the sample population of (M.L.I.D) (administrative instructional and vocational) towards the deaf?

3) What is the educational attitudes level of members of (M.L.I.D) toward the deaf?

4) Are there significant differences among the members of population of (M.L.I.D) affect their level of attitudes that consoled to the different variables (gender, age, level of education)?

A lot of studies and researches investigated the topic of society member's attitudes toward disabled, especially the deaf in many countries and all over the world (nationally, Arabian and international). They showed a lot of negative and positive types of attitudes toward different kinds of deaf people. They also showed up different results for these types of attitudes. It seems to be that the importance of these studies is achieved through the 
results that concluded to it. It also explained and determined positive and negative attitudes, which can master the professional and learners or decision makers on the two levels (academic and vocational) to organize schedules and projects to help these categories in order to make positive exchanges in the relationship and social connection with them and to change the negative attitudes to positive ones and also to achieve the best level of adaption with them in their personal and social life in the same way. In favor the objectives of societies in general.

One of the international studies which investigated the attitudes of people toward the deaf held by (Powell, 2011) in the local schools in New Zeeland, the researchers used different programs, ways and procedures which are followed by interviews and a survey in depth by sharing samples of deaf students and their mates who have the ability to hear. The aim of the study was to determine the effectiveness of these programs, ways, procedures to enable the deaf students to learn, share and raise their awareness of their needs and their social and academic experiences like others. It also aimed at determining the barrier that can stand in their way to achieve the goals of the programs in order to deal with it to improve the attitudes of deaf people toward themselves and other people toward them.

In the same way, there was a study by Greg (2015) from Rochester Institute for Researches, Godwit University, California, America which was entitled "the Social perception towards the deaf people, how it can affect in over developing identity in Deaf Society?". It was aimed to reveal the effective role of the deaf society to develop the personal identity of the deaf people, because the social attitudes and stereotype image of normal people towards the deaf could have a prejudice to them. Besides that, there are many different negative attitudes in the deaf society themselves. The study also revealed about reasons that can affect the adaption of the deaf people and develop their positive identity.

Another study by Lucy Mwangi (2013) from Brunel University, London which was superscripted "Teaching Special Disabled People in Public Schools in Kenya". The study focused on discovering the government policies in teaching the deaf people at primary government schools in Kenya. Moreover, on forming these policies by the Kenyan government to achieve the national goals in this field. Moreover, to understand teacher's attitudes who also applied the basic achievement program for the deaf in primary schools. The sample of the study consisted of 27 schools from different villages and cities in Kenya. The data gathered from those school teachers by filling 159 questionnaire through responsible people in addition to 9 interviews in depth. This study showed that the government policies are ambiguous and difficult to apply by teachers, and it failed to mention the key words and general procedures to achieve the basic needs in teaching the deaf. The study also brighten up that there were essential needs to apply Individualized Instructional Plan because there were ambiguous in the definitions of the government programs, which attached to deaf people. This is the actual indicator about the negative attitudes towards deaf people in Kenya.

To recognize the social imagination among the deaf and normal people, Rebecca Carol (2015) carried out a study entitled "Social Interaction between Deaf and Normal People". The researcher examined the personal experiences of normal people in their interaction with the culture of deaf people in order to improve the deaf people current. She found that there was a huge gap in their information about deaf people. They also don't feel relax when they interact with them. She added that normal people need to understand the needs of deaf people. The study treated with 582 students of Mississippi University who can hear.

For more focusing and spotting on teacher's attitudes (Claire Ting \& Linda Gilmore, 2012) from Kwanza Land Technology University, Australia, made a study about teacher's attitudes towards teaching English Sign Language for deaf people. The study was to find out the teachers attitudes towards teaching the Australian Sign Language to deaf in contrasting with Australian students who speak Polish. The sample was consisted of 200 teachers who were in the third and the fourth years of their experiences in working at the university. They designed a questionnaire for this purpose to measure teacher's attitudes and to make a priority scales; teacher's confidence and their expectations. The study also showed that teachers have high priorities to teach Australian Sign Language for the deaf more than teaching Polish students' English language. They also had more confidence by themselves to teach deaf people than teach Polish students.

In the Arab countries, there was a study by AL-Othman (2004) from Lincoln University entitled "Academic Teaching for Deaf Students, New Images between Teachers and Parents in the Kingdom of Saudi Arabia". This study focused on teaching deaf students. In particular to determine the theoretical and practical reasons which affect in teaching deaf students at primary schools. It also focused at knowledge, gadgetry and teaching, in order to establish a program which contains the main effective factors to qualitative services that need for teaching the deaf. 
Another study by AL-Khateeb (2008) about "the Attitudes of Society members towards Persons with Special Needs". It focused on the nature of attitudes, types and how to form it with an explanation for some issues with regarding to attitudes. The study showed that the main factors which obstruct to precede instructional and developing services to the deaf in the Arab countries. These obstacles are results of thoughts and wrong concepts that carried by people towards the deaf disability. These thoughts and attitudes didn't stand to exact knowledge because the reasons for these handicap and its components may give people modality images about disabled people.

There was also a blog about this domain entitled "the Society View toward People with Special needs; assist not Indignity, 2014". The study showed that there were negative teaching, vocational and social factors on deaf people. We all need to thwart against these factors to understand the best procedures to perceive the handicap to make a kind of accommodation with persons with special needs; deaf people who are part of them, in order to overpass all traditional bad ideas and views towards them. Also to adapt legislations, in order to change the stereotype of the deaf people.

In the Hashemite Kingdom of Jordan, there were many studies about different subjects towards attitudes to deaf people and their findings. There was a study byAL-Khateeb and Akef (2009) entitled "the Attitudes of Society People toward People with Special Needs". It showed the importance of recognizing the peoples' attitudes toward handicap and its categories. This may lead us to understand different forms of services and legislations that the community has, to different types of handicaps under what is known by "Community Based Rehabilitation". In order to achieve a kind of equality and protection human rights for disabled people, by sharing all different community sections. The study also emphasized the importance of enriches people and supply them to modification concepts and attitudes about handicaps and every miss concept related to it.

In her study, AL-Haniny (1989) aimed to reveal the attitudes of headmasters, headmistresses and teachers of primary schools towards inclusion motor disabled students in public schools and the effect of different variables (gender, academic qualification, experience years and position job) on forming attitudes towards including motor disabled students in public schools in Zarqa, Jordan. The sample of the study consisted of 234 teachers and 66 headmaster and headmistresses. The data gathered by researcher by using special scale formed by her. It consisted of 150 clauses. The results revealed that the two variables (gender and position job) were positive to include motor disabled students in public schools. On the other hand, the two other variables (academic qualification and experience years) and the interaction between gender, academic qualification and job position didn't have any effect on the attitudes scale.

\section{Method}

In this chapter, the researchers will describe in details the methodology used in this study, the study population and its sample. Next, the researchers explain the study tools and the way of data collection. After that, they will discuss the statistical treatment that is used to analyse the collected data. In the final section, the validation of the questionnaire and the reliability analysis that is applied will be clearly stated.

\subsection{Study Tools and Data Collection}

The current study consists of two aspects, theoretical and practical. In the theoretical aspect, the researchers relied on the scientific studied that are related to the current study. Whereas in practical aspect, the researchers relied on descriptive and identical methods using the practical manner to collect, analyse data and answer the questions. The data collection, manners of analysis and programs used in the current study are based on two sources:

-Secondary sources: books, journals, and theses to write the theoretical framework of the study.

-Primary sources: a questionnaire that was developed by the researchers to reflect the study objectives and questions. The questionnaire was developed by revising the previous literature and studies such as AL-Khateeb (2009), Abu-Futouh (2011), Greg (2015).

The questionnaire instrumental sections are as follows:

-Section One: Demographic Variables. The demographic information was collected according to gender, age, the natural relationship with deaf and the academic level.

-Section Two: Attitudes of H.L.I.D toward deaf people. This section was measured through 32 items on a Likert-type scale as follows:

- Agree: 3 
Indifferent: 2

○ Disagree: 1

The items were divided into two dimensions:

1) The first dimension related to social dimensions include 16 items.

2) The second dimension related to educational attitudes include 16 items.

\subsection{Study Approach}

The current study adapted the descriptive approach involving collecting data in order to test hypotheses or to answer questions concerned with the current status of the subject of the study: "The Attitudes of the Holy Land institute for the Deaf-Salt, Jordan towards Deaf socially and educationally." The researchers design chosen for the study is the survey presented. The survey is an attempt to collect data from members of a population study in order to determine the current status of that population with respect to one or more variables. The survey research of knowledge at its best can provide very valuable data. The researchers designed a survey instrument that could be administrated to selected subjects. The purpose of the survey instrument was to collect data about the respondents on the attitudes of the Holy Land Institute for the deaf- salt, Jordan towards deaf socially and educationally.

To test the questionnaire for clarity and to provide a coherent research questionnaire, a macro review that covers all the research constructs was thoroughly performed by academic reviewers from Princess Rahma CollegeAL-Balqa Applied University specialized in Special Education and Social Work. They considered the standard 80 for each item to be suitable. Some items were added, while others were dropped based on their valuable recommendations. Some others were reformulated to become more accurate to enhance the research instrument. The academic reviewers are 11 persons.

\subsection{Study Population and Sample}

The study population consisted of 90 persons; all people who work in H.L.I.D. The researchers handed all the questionnaires to all workers in the institution and received 69 ones which achieved the circumstances and required conditions of the standard 80 . Table 1 shows the demographic variables of the study (gender, age, the nature of relationship with the deaf and the academic level).

\subsection{Demographic Variables}

Table 1 shows the demographic variables of the study (gender, age, the nature of relationship with the deaf and the academic level).

Table 1. Demographic variables of the study

\begin{tabular}{lll}
\hline Variables & Frequents & Percentage \\
\hline Gender & 15 & 21.7 \\
Male & 54 & 78.3 \\
Female & 69 & 100.0 \\
Total & & \\
Age & 26 & 37.7 \\
$23-28$ year & 14 & 20.3 \\
$29-33$ year & 29 & 42.0 \\
$34-$ and over & 69 & 100.0 \\
Total & & \\
The nature of the relationship with deaf & 30 & 43.5 \\
Teacher & 10 & 14.5 \\
Friend & 12 & 17.4 \\
Executive & 3 & 4.3 \\
Official & & \\
\hline
\end{tabular}




\begin{tabular}{lll}
\hline Others & 14 & 20.3 \\
Total & 69 & 100.0 \\
Level of education & & \\
Elementary & 5 & 7.2 \\
Secondary & 19 & 27.5 \\
Academic & 45 & 65.2 \\
Total & 69 & 100.0 \\
\hline
\end{tabular}

Table 2 shows the consistency of each item of the scale with its dimension to which it belongs, they used link transactions between items in the scale by using Alpha Cronbach Co- efficient. Table 2 shows the results.

Table 2. The stability co-efficient using Cronbach Alpha

\begin{tabular}{lll}
\hline Studying Variables & Items & Stability co efficient using Cronbach Alpha \\
\hline Social attitudes toward deaf & 16 & $\mathbf{0 . 8 0}$ \\
Educational attitudes toward deaf & 16 & $\mathbf{0 . 7 7}$ \\
Total of all attitudes & $\mathbf{3 2}$ & $\mathbf{0 . 8 4}$ \\
\hline
\end{tabular}

According to Table 2, the amount of Cronbach Alpha for each subsidiary dimension is between $0.77-0.80$. The value of the stability co efficient was also calculated using Alpha Cronbach for the total grade of the scale (the scale correcting key).

Analysis of Co-Variance two Way ANACOVA and Two Way ANOVA.

Relative importance, assigned due to:

Class Interval=Maximum Class-Minimum Class

Number of Levels

$3-1=2=0.66$

$3 \quad 3$

- $\quad$ The low degree from 1-1.66

- $\quad$ The medium degree from $1.67+0.66=2.33$

- The high degree from 2.34-3.00

\section{Results}

According to the purpose of the research and the research framework presented in the previous chapter, this chapter describes the results of the statistical analysis for the collected data according to the research question. The data analysis includes a description of the Means and Standard Deviation for the questions of the study, Two Way ANACOVA AND Two ways ANOVA were used.

\subsection{Descriptive Analysis of Study Questions}

Question One: What is the social and educational attitudes level of members of M.L.I.D in general? 
Table 3. Arithmetic mean and Standard deviation of the level of social and educational attitudes of (M.I.L.D) toward deaf people

\begin{tabular}{llllll}
\hline No. & Attitudes & $\begin{array}{l}\text { Arithmetic } \\
\text { means }\end{array}$ & $\begin{array}{l}\text { Standard } \\
\text { deviation }\end{array}$ & Class & Level of directions \\
\hline 2 & Educational & 2.49 & 0.26 & 1 & High \\
1 & Social & 2.24 & 0.19 & 2 & Medium \\
& Total degree of the scale & 2.36 & 0.16 & & High \\
\hline
\end{tabular}

Table 3 shows that arithmetic means for the attitudes range between 2.24 and 2.41. The attitudes get about 2.36; it's a high level. The educational attitudes came in the first class. It got the highest arithmetic means about 2.49 and standard deviation about 0.26 . The social attitudes came in the second class with means 2.24 and standard deviation 0.19 .

Question Two: What are the levels of educational and vocational attitudes of members of M.L.I.D towards the deaf?

The study used the arithmetic means and standard deviation to show the results about the social attitudes of M.L.I.D toward deaf people as follow in Table 4.

Table 4. Means and standard deviation for responses of sample study about the items of M.L.I.D towards deaf people socially in descending order

\begin{tabular}{|c|c|c|c|c|c|}
\hline No. & Item & Average arithmetic & $\begin{array}{l}\text { Standard } \\
\text { deviation }\end{array}$ & Class & $\begin{array}{l}\text { The level of } \\
\text { attitudes }\end{array}$ \\
\hline 1 & I accept deaf and like to talk with him & 3.00 & 0.00 & 1 & High \\
\hline 2 & I know some signs of sign language & 2.94 & 0.34 & 2 & High \\
\hline 13 & Deaf tries to know what others said & 2.88 & 0.40 & 3 & High \\
\hline 4 & $\begin{array}{l}\text { I like to play with deaf and share with him every } \\
\text { activity }\end{array}$ & 2.84 & 0.44 & 4 & High \\
\hline 10 & Deaf can appreciate others reactions & 2.70 & 0.58 & 5 & High \\
\hline 14 & Deaf deals with others and can expresses himself & 2.67 & 0.70 & 6 & High \\
\hline 16 & $\begin{array}{l}\text { Deaf usually plays the social role that was expected } \\
\text { from him }\end{array}$ & 2.64 & 0.71 & 7 & High \\
\hline 11 & Deaf often optimistic & 2.46 & 0.76 & 8 & High \\
\hline 7 & Deaf is clever and his self confidence low & 2.32 & 0.87 & 9 & Medium \\
\hline 9 & Deaf isn't introvert and unsocial & 2.26 & 0.93 & 10 & Medium \\
\hline 12 & Deaf usually misbelieve with others & 2.17 & 0.86 & 11 & Medium \\
\hline 6 & $\begin{array}{l}\text { Deaf feels weakness and doesn't have self- } \\
\text { confident }\end{array}$ & 1.64 & 0.87 & 12 & Low \\
\hline 3 & I feel worried from deaf and cant interact with him & 1.35 & 0.68 & 13 & low \\
\hline 8 & I feel that deaf social class lower than me & 1.33 & 0.63 & 14 & Low \\
\hline 5 & Deaf prefers to sit alone most of times & 1.30 & 0.63 & 15 & low \\
\hline 15 & $\begin{array}{l}\text { Deaf describes with a lot of bad names such as } \\
\text { (deformity, retardant, powerless,... }\end{array}$ & 1.26 & 0.63 & 16 & low \\
\hline & The general average arithmetic & 2.24 & 0.19 & 1 & Medium \\
\hline
\end{tabular}

Table 4 shows that arithmetic mean for attitudes of M.L.I.D towards deaf people were within the levels of high, medium and low. They were between $1.26 \& 3.00$. The arithmetic mean for social attitudes was 2.94. It's from medium level. Item 1 was the highest arithmetic mean 3.00 with standard deviation 0.00 which was from the 
highest level. In the second-class item 2 with arithmetic mean 2.94 and standard deviation 0.34, this was from the high level. In the third-class item 13 with arithmetic mean 2.88 and standard deviation 0.40 , this was from high level, too. These are the main social attitudes towards the deaf in the study population of L.M.I.D. The social attitudes were in the medium level in the following items 7, 9, and 12. Whereas item 7 with arithmetic means 2.32 and standard deviation 0.87, this was medium level. Next, item 9 with arithmetic means 2.26 and standard deviation 0.93 and also medium level. Item 12 with arithmetic means 2.17 and standard deviation 0.86 with medium level. In the last class, item 15 with arithmetic means 1.26 and standard deviation 0.63 , this was a low level. In the penultimate class was item 5 with arithmetic mean 1.30 and standard deviation 0.63 , it was from the lowest level. As a final result, it expressed that the drooping of negative attitudes level reflected high social positive attitudes towards the deaf by M.L.I.D.

Question three: Are there significant differences among the members of population of M.L.I.D effect their level of attitudes that consoled to the different variables (gender, age, level of education)?

The study used the arithmetic mean and standard deviation to show the results about the educational level of M.L.I.D towards the deaf as shown in Table 5, they are put in descending order.

Table 5. The educational level of M.L.I.D towards the deaf in descending order

\begin{tabular}{|c|c|c|c|c|c|}
\hline No. & Item & $\begin{array}{l}\text { Standard } \\
\text { deviation }\end{array}$ & $\begin{array}{l}\text { Means } \\
\text { arithmetic }\end{array}$ & Class & $\begin{array}{ll}\text { Level of } \\
\text { directions }\end{array}$ \\
\hline 2 & Deaf can learn different skills & 2.94 & 0.34 & 1 & High \\
\hline 1 & I know positive characteristics in deaf people & 2.81 & 0.55 & 2 & High \\
\hline 3 & I like to teach deaf \& feel relax & 2.78 & 0.62 & 3 & High \\
\hline 4 & I use sign language accurately & 2.78 & 0.59 & 3 & High \\
\hline 16 & Deaf feels save inside class & 2.70 & 0.67 & 5 & High \\
\hline 9 & Deaf depends on his hands movements in learning & 2.65 & 0.70 & 6 & High \\
\hline 12 & Deaf can differentiate when others noticed him inside class & 2.65 & 0.66 & 6 & High \\
\hline 15 & Deaf depends greatly on his eyes in learning & 2.65 & 0.70 & 6 & High \\
\hline 13 & Deaf behaves diplomacy through exams & 2.48 & 0.74 & 9 & High \\
\hline 8 & Deaf masters reading, writing \& math & 2.41 & 0.79 & 10 & High \\
\hline 7 & Deaf faces some troubles to understand some learning skills & 2.38 & 0.79 & 11 & High \\
\hline 6 & The sign language doesn't enough for all learning skills & 2.26 & 0.90 & 12 & High \\
\hline 14 & Deaf does his homework accurately & 2.23 & 0.81 & 13 & Medium \\
\hline 10 & Deaf handicaps' effect the level of his learning & 2.19 & 0.94 & 14 & Medium \\
\hline 5 & All deaf people master the sign \& lips language & 1.97 & 0.87 & 15 & Medium \\
\hline \multirow[t]{2}{*}{11} & Deaf graduation is low because of his handicap & 1.93 & 0.93 & 16 & Medium \\
\hline & The general average arithmetic & 2.49 & 0.26 & & High \\
\hline
\end{tabular}

Table 5 shows that the educational attitudes towards the deaf among M.L.I.D were within high and medium levels. They were between $1.93 \& 2.94$. The standard deviation for the educational attitudes is 2.49 , this was from high level.

Item 2 showed the highest standard deviation 2.94 and arithmetic mean 0.34, this was from the high level.

In the second class came item 1 with standard deviation 2.81 and arithmetic mean 0.55 that was from the highest level.

In the third class came item 3 with standard deviation 2.78 and arithmetic mean 0.62 that was from the low level.

On the other hand, the educational attitudes toward deaf people appeared in items $6,14,10,5$, and 11. In the last class, came item 11 with standard deviation 1.93 and arithmetic mean 0.93 this was from the medium level. In the penultimate class, came item 5 with standard deviation 1.97 and arithmetic mean 0.87 this was from medium level which said All deaf people master the sign \& lips language. 
As a whole, the results of the educational attitudes of M.L.I.D towards the deaf were high.

Question Four: Are there significant differences among the members of population of M.L.I.D affect their level of attitudes that due to the different variables (gender, age, and level of education)?

The study used the Two Way ANACOVA test to show the results about the statistically significance difference about the educational and social attitudes toward deaf people as a result for different variables (gender, age, level of education).

Table 6 shows the results of the analysis of the mixed non-multivariate test Two Way ANOVA to identify the differences in the trend levels of M.L.I.D about the social and educational attitudes toward deaf people as a result for different variables (gender, age, level of education).

Table 6. Rests for mixed non-multivariate test Two Way ANOVA

\begin{tabular}{|c|c|c|c|c|c|c|}
\hline Variables & Source of contrast & Total squares & $\begin{array}{l}\text { Degrees of } \\
\text { freedom }\end{array}$ & $\begin{array}{l}\text { The average of } \\
\text { squares }\end{array}$ & $\mathbf{F}$ & $\begin{array}{l}\text { Statistical } \\
\text { significance }\end{array}$ \\
\hline & Gender & 0.035 & 1 & 0.035 & 1.064 & 0.306 \\
\hline Social & Age & 0.027 & 2 & 0.013 & 0.405 & 0.669 \\
\hline \multirow[t]{5}{*}{ Attitudes } & Academic level & 0.296 & 2 & 0.013 & 0.405 & 0.669 \\
\hline & False & 2.063 & 2 & 0.148 & 4.52 & $* 0.015$ \\
\hline & Total & 347.234 & 63 & 0.033 & & \\
\hline & Total of correction & 2.407 & 69 & & & \\
\hline & Gender & 0.032 & 68 & & 0.484 & 0.489 \\
\hline \multirow{5}{*}{$\begin{array}{l}\text { Educational } \\
\text { Attitudes }\end{array}$} & Age & 0.036 & 1 & 0.032 & 0.269 & 0.765 \\
\hline & Educational level & 0.15 & 2 & 0.018 & 1.119 & 0.333 \\
\hline & False & 4.233 & 2 & 0.075 & & \\
\hline & Total & 431.746 & 63 & 0.067 & & \\
\hline & Total of correction & 4.549 & 69 & & & \\
\hline
\end{tabular}

*Significant at level (0.05) and down.

The study used Two Way ANACOVA test to identify the statistical significant differences.

There were no significant differences for gender. It showed that $F$ value for variables $(0.484,1.064)$ for all attitudes (social \& educational attitudes); also, it's significant at level 0.05 and below. The study also showed that there were no significant differences for age. It showed that $F$ value for variables $(0.269,0.405)$ for all attitudes (social and educational attitudes) toward deaf people. Also, it's significant at level 0.05 and below. The study also showed that there were significant differences for the educational level. It showed that $\mathrm{F}$ value was 4.52. To identify the source of differences, researchers used (Shiva Comparison Test) that appeared in Table 7. The results also showed that there were no significant differences according to academic level. It showed that $\mathrm{F}$ value was 1.119 , which was (the educational attitudes) towards the deaf people. It wasn't significant at level 0.05 and below.

Table 7 shows results from the the post Shiva Comparison Test was used to identify the sources of differences of social attitudes toward the deaf with referring to academic level. 
Table 7. Post Shiva Comparison Test

\begin{tabular}{llll}
\hline (I) Academic level & (J) Academic level & $\begin{array}{l}\text { The difference between the average } \\
(\mathbf{I}-\mathbf{J})\end{array}$ & Statistical significance \\
\hline Primary & Secondary & $.05329-$ & .557 \\
& Academic and above & $.17222^{*}-$ & $* .046$ \\
Secondary & Primary & .05329 & .557 \\
& Academic and above & $.11893^{*}-$ & $* .018$ \\
Academic and above & Primary & .17222 & $* .046$ \\
& Secondary & .11893 & $* .018$ \\
\hline
\end{tabular}

*Significant at level (0.05) and below.

The results from Table 7 show that the social attitudes according to academic level were for the level of academic and above; this shows that the group which has a high academic level, has a high social attitude towards deaf in M.L.I.D and higher than those with primary or secondary levels. This result disagrees with the results of Ting and Glimore (2014) study which clarifies that teachers in general have low academic predictions and behaviors with the deaf in comparison with normal people. This is due to the lack of their information towards deaf students.

\section{Discussion}

The results showed for the first question showed that social and academic attitudes for the study sample were high. The educational attitudes got the first class with high level and the social attitudes in the second class with medium level. The variance was due to the educational role which was played by the study sample. This is may be because they work in the M.L.I.D, they are always together or to their accurate with communication skills with deaf people. This result agrees with AL-Jasem (1988) which relevant to modify workers attitudes toward deaf people.

On the other hand, the results for the second question which was attached to the social attitudes were medium level. These results may due to the general social view towards deaf. A lot of people don't interact with the deaf directly. Moreover, they may need a long time to interact and deal with them by knowing them and their language to understand each other. The study population also noticed that the deaf people have a lot of doubts, this may lead to ignore them and don't cope with them. This result agrees with Rebecca (2015) which revealed that the person who doesn't treat deaf or doesn't understand their needs, should have the skills of how to deal with deaf. But in this study, the workers know a lot about how to cope with deaf and also their characteristics. Whereas, AL-Khateeb's (2009) study confirmed that caring socially of this group, saving care also for them and all what they need opportunities, services, ... was an essential demand to this group. Disabled people have rights and duties like all members of the community and they need to be included and adapted.

Finally, for the third question, the results showed that the educational attitudes for workers, administers, educators and professionals were raised. This was referred to the knowledge they had about the reality of the deaf, their needs, the reasons of disability, dealing with them and prevent this handicap. Also, the result may due to the enjoyable and the desire of the workers to teach the deaf people. Whereas the deaf people acquired educational skills, through the long experience by dealing with them. In addition to the Nobel goal (the educational letter). Moreover, the design of workers to treat deaf people and their experience of how to cope with them may also lead to raise this level. The results of this study agreed with (AL-Othman, 2014) which emphasized the need for special curriculum, special modal, and strategies that depend on knowing and understanding the deaf students. This result also emphasized the necessity of special relationship between teachers and families to understand and know the characteristics of deaf people. It also confirmed the necessity of using special equipment's to the deaf people like teaching workers the sign language in order to build a kind of confidence between the two groups and also to keep away from fear for the deaf people towards teachers. This is one of the M.L.I.D objectives which tried to emphasize in its curriculum and procedures through the sign language and special ways and methods to the deaf people. Whereas there were residential institution for a limit period of time in this institution. Also employed many deaf workers and technical who have an experience in the external social life. And therefore, exchange their educational experiences to the deaf people that there are deaf workers with master degree. This justifies the positive educational attitude. 


\subsection{Recommendations}

Finally, according to the results, researchers recommend the following:

1) Further research to identify the types of society attitudes in general towards the deaf (socially, educationally, morally and professionally). This is because these attitudes play significant role in changing the level of modifying towards the deaf. This may gain deaf people their daily life social skills to depend on themselves to a high level in order to achieve their different needs and manage their lives (community Based Rehabilitation).

2) Implementing the modal of M.L.I.D in behaving and socializing with the deaf as a successful modal which gives them the opportunity to cope with others socially and educationally. This modal may be patterned to other centers which have the same job.

3) Training and conducting conferences and special workshops which are dedicated for ways of behavior to cope with deaf people. This may help us to spread the culture of how to communicate with deaf people and to teach the necessary skills for their families. Moreover, teaching families the suitable modals to teach the deaf the long and short objectives by handing their parents these objectives and goals monthly.

\section{Refrences}

Abu AL-Futouh, A. (2011). The attitudes of teachers of primary schools towards include autism students with normal people in public schools. In The Second International Science Conference for Health Psychology (Vol. 1, pp. 415-464). Psychology study, Faculty of Education, Banha University, The Egyptian Arabic Republic.

Al Othman, A.-A. (2014). Inclusive education for deaf students in Saudi Arabia: Perceptions of schools, principals, teachers and parents. University of Lincoln, UK.

AL-Khateeb, A. A. (2009). Attitudes towards Exceptional persons. In Forum: Studies and Reaearches.

AL-Malah, T. (2015). The characteristics of Hearing impairment people. Tamer AL-Magawrey.

AL-Malah, T. (2016). The Hearing Impairment between qualifying and technology. Faculty of Education, Alexandria University, Egypt.

AL-Rosan, F. (1998). The psychology of up normal people, an introduction to Special Education, Dar AL-Fkher for printing, spreading and distribution books. Amman, Jordan.

Ashley, T. (2012). The University of Southern Mississippi The Aquila Digital Community perceptions of the Deaf among various University social groups.

Assaleh, K., \& Al-Rousan, M. (2005). Recognition of Arabic Sign Language Alphabet using Polynomial Classifiers. EURASIP Journal on Applied Signal Processing, 2005(13), 2136-2145.

Attitudes of the society towards disabled people and its effect. (n.d.). Bulletin. Retrieved from http://www.google.com

Attitudes of the society towards disabled people. (n.d.). Retrieved from http://www.google.com

Greg, F. (2015). Social perception toward deafness: How could it influence deaf identity development and deaf community. Gallaudet Chronicles of Psychology, 3(1), 3-10.

Haj-Mousa, E. (2016). The effectiveness of Hearing Impairment and Visual Impairment on Personally Disabled (case study of disabled people who registered at Federation of Deaf and Union of the Blind, Bod Madny (March-December 2012). Journal of Psychology and Educationally Science, 2(1), 117-118.

Hankins, R. (2015). Social Interaction between deaf and hearing people. Oxford University of Mississippi.

Hearing Disability. (n.d.). Mofadee, Algeria. Retrieved from http://www.google.com

Mprah, W. K. (2013). Exploring knowledge and attitudes towards HIV/AIDS among deaf people in Ghana. Disability, CBR \& Inclusive Development, 24(2), 22-39.

Mwangy, L. (2013). Special Needs Educations (SNE) in Kenyan Public Primary Schools: Exploring Government Policy and Teachers understanding. Brussels University, London.

Nteel, R., \& Al-Holo, M. (2007). The distinguishing features for the deaf, visual \& moving impairment people in view of some variables. Journal of the Islamic University (series of Islamic studies), 15(2), 875-924. 
Powel, R. (2011). Floating in the mainstream: New Zealand Deaf Students, learning and Social Participation Experiences Interiorly Education. Griffitt University.

Prem, S. (2017). Psychosocial perspectives on support for children with special needs inclusive education. International Journal of Science and Research, 6(1).

Reports of the Holly Lands Institute for The Deaf. (1964-2017). Salt, Jordan.

The Social and Psychology characteristics for the Deaf people. (n.d.). Retrieved December 1, 2017 from http://www.google.com/site/alasdamen/home-/anwa-alaaqte-alsmyte/alkhsays-alajtmayte-walnfsyh-llmwqy

Ting, C., \& Gilmore, L. (2012). Attitudes of preserves teachers towards teaching deaf and ESL students; Australian. Journal of Teachers Education, 37(12).

\section{Copyrights}

Copyright for this article is retained by the author(s), with first publication rights granted to the journal.

This is an open-access article distributed under the terms and conditions of the Creative Commons Attribution license (http://creativecommons.org/licenses/by/4.0/). 